\title{
Current Research and Development in Abrasive Water Jet Machining (AWJM): A Review
}

\author{
Sudhakar R. Lohar ${ }^{1}$, Pravin R. Kubade ${ }^{2}$ \\ ${ }^{1,2}$ Shivaji University, K.I.T.'s College of Engineering, Kolhapur-416234, Maharashtra, India
}

\begin{abstract}
Abrasive Water jet machining (AWJM) is a non-conventional manufacturing process, where material is removed from the work piece by impact erosion of pressurized high velocity water stream mixed with high velocity grit abrasives on a work piece. There are so many process parameters which affect the quality of machined surface cut by AWJM. But, the traverse speed, hydraulic pressure, stand-off distance, abrasive flow rate and type of abrasive are important. However, the important performance measures in AWJM are Material Removal Rate (MRR), Surface Roughness (SR), Kerf width, Depth of cut. This paper reviews the research work carried out from the inception to the development of AWJM within past few years. It reports on the AWJM research relating to performance measures improvement, monitoring and process control, process variables optimization. A wide range of AWJM industrial applications for variety of materials are reported with variations. The paper also discusses the future trend of research work in the area of $A W J M$.
\end{abstract}

Keywords: AWJM, Process parameter, Process optimization, Monitoring, Control.

\section{Introduction}

Manufacturing industry is becoming more time conscious and quality oriented with the advancement in global economy. This becomes necessary to use non conventional machining processes such as Chemical Machining, Laser Machining, Electric Discharge Machining, Abrasive Water Jet Machining, etc. Abrasive water jet machining (AWJM) is a non-conventional machining process that employs highpressure water for producing high velocity stream, entrained with abrasive particles for a wide variety of materials ranging from soft to hard. AWJM is a versatile machining process primarily used to machine materials ranging from soft to hard like titanium, inconel, etc. hard and difficult to machine materials [1].

Abrasive water jet machining makes use of the principles of both abrasive jet machining and water jet machining. The first industrial application manufactured by McCartney Manufacturing Company and installed in Alto Boxboard in year 1972. The invention of the abrasive water jet in 1980 and in 1983 the first commercial system with abrasive entrainment in the jet became available. This technique is mainly suitable for softer, brittle and fibrous materials. This process operates without heat generation so machined surface is free from heat affected zone (HAZ) and residual stresses. AWJM has higher machining versatility and better flexibility. The major drawback of this process is, it generate loud noise and a messy working environment. AWJM have certain advantageous characteristics, which turns to achieve significant penetration into manufacturing industries.

- Faster set-up and programming

- Less sensitive to material properties as it does not cause chatter

- Very little fixturing for most parts

- Machine virtually any 2D shape on any material

- No heat affected zone (HAZ) on part

- Machine thick plates

AWJM is normally used for applications like Paint removal, Cutting frozen meat, Surgery, Cutting, Pocket Milling, Turning, Drilling, Textile, Leather industry. Materials which are cut by AWJM are Steels, Non-ferrous alloys, Super alloys, Exotic materials, Ti alloys, Ni- alloys, Polymers, Metal Matrix Composite, Ceramic Matrix Composite ,high tech ceramics, Concrete, Wood, Plastics, Metal Polymer Laminates, etc.

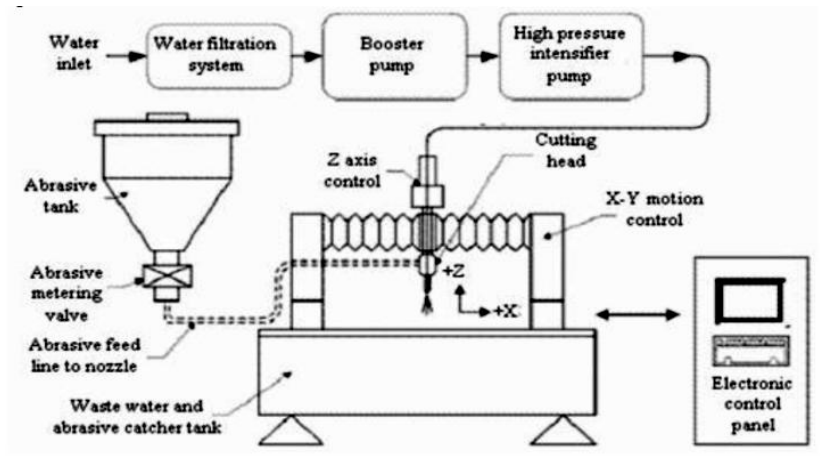

Figure 1: Abrasive Water Jet Machine Schematic Diagram

Non-traditional machining like AWJM has grown out of the need to machine these exotic materials. The problems of high complexity in shape, size and demand for product accuracy and surface finish can be solved through AWJM.

Abrasive Water jet Machining (AWJM) has also made its presence felt in the new fields such as sports, medical and surgical, instruments, optical, including automotive R\&D areas and machining geometrically complex or hard material components, that are precise and difficult-to machine such as heat treated tool steels, titanium, composites, super alloys, ceramics, carbides, heat resistant steels etc. being widely used in die and mold making industries, aerospace, aeronautics and nuclear industries.

\section{Literature Review}

A literature review of the recently published research work on AWJM is carried out to understand the research issues involved and is presented here,

Guru Sewak Kesharwani [1] investigated on using Non- 


\section{International Journal of Science and Research (IJSR) \\ ISSN (Online): 2319-7064}

Index Copernicus Value (2013): 6.14 | Impact Factor (2014): 5.611

spherical (Triangular \& Trapezoidal) Sharp edge shape ceramics abrasive particle as abrasive for cutting surface material modeled is a titanium based super alloy (Ti-6Al$4 \mathrm{~V}$ ) extensively used in the aerospace industry. It is observed that traverse speed is an important parameter in the case of controlled depth milling (CDM) for AWJM. By experiment they found that with the modified setup of abrasive feed system, a reduction of approximately $20 \%$ time for milling the Ti-6Al-4V sample is achieved. It is also confirmed that surface waviness can be reduced as traverse speed is increased by using modified abrasive feeding system.

Chithirai Pon Selvan M et al. [2] has carried out study on the influence of process parameters on the irregularities of alumina ceramics surfaces generated by abrasive water jet. Taguchi's design of experiments was carried out in order to collect surface roughness values. Experiments were conducted in varying water pressure, nozzle traverse speed, abrasive mass flow rate and standoff distance for cutting alumina ceramics using abrasive water jet cutting process. They concluded that a combination of high water pressure, more abrasive mass flow rate, low traverse speed and short standoff distance be used to produce more surface smoothness.

Ramprasad et al. [3] carried out work to optimize the metal removal rate (MRR) of Stainless steel 403 in abrasive water jet machining using ANOVA and Taguchi method. The MRR is optimize by using three parameters water pressure, abrasive flow rate and stand-off distance and L9 orthogonal array of Taguchi method used to analyze the result. They concluded that the water pressure (WP) was the most influencing factor for stainless steel 403 work material followed by stand-off distance and abrasive flow rate.

Vishal Gupta et al. [4] investigated on Minimization of kerf taper angle and kerf width using Taguchi's method in abrasive water jet machining of marble. They considered three process parameters viz. water pressure, nozzle transverse speed and abrasive flow rate. Experiments were conducted according to Taguchi's design of experiments. It was concluded that the nozzle transverse speed was the most significant factor affecting the top kerf width, the kerf taper angle.

P. Shanmughasundaram [5] presented the influence of abrasive water jet machining (AWJM) parameters such as water pressure, standoff distance, and traverse speed each at three different levels on the surface roughness (SR) of the Al- graphite composites which are fabricated through the squeeze casting method. The experiments were conducted using L9 Taguchi technique. It was observed that the contribution of water pressure on surface roughness found to be more significant than traverse speed and standoff distance. It was confirmed that obtained mathematical modeling can be successfully employed to predict the surface roughness of composites.

D. Sidda Reddy et al. [6] studied optimization of the process parameters on abrasive water jet machining (AWJM) using Taguchi method for Inconel $800 \mathrm{H}$ material. The approach used is based on the analysis of variance (ANOVA) and signal to noise ratio (SN Ratio) to optimize the AWJM process parameters for effective Material Removal Rate (MRR) and Surface Roughness (SR). They confirmed that determined optimal combination of AWJM process parameters satisfy the real need for machining of Inconel $800 \mathrm{H}$ in actual practice.

M. Sreenivasa Rao et al. [7] investigated the effect of process parameters, viz water pressure, Traverse speed and Standoff distance, of Abrasive Water Jet Machine (AWJM) for mild steel (MS) on surface roughness (SR). Taguchi's method, analysis of variance (ANOVA), F-test and signal to noise ratio (SN Ratio) are used to optimize the considered parameters of Abrasive Water Jet Machining. In Taguchi's design of experimentation, L9 orthogonal array is formulated and concluded that water pressure and transverse speed are the most significant parameters and standoff distance is sub significant parameter.

Ushasta Aich et al. [8] carried out experiments on cutting of borosilicate glass by AWJM. Depth of cut is measured with different machine parameter settings as water pressure, abrasive flow rate, traverse speed and standoff distance. Optimum condition of control parameter setting is also searched through particle swarm optimization (PSO).Also, scanning electron microscopic (SEM) image reveals to some extent, and the nature of cut surface and erosion behavior of amorphous material qualitatively.

K.S. Jai Aultrin and M. Dev Anand [9] investigated work on Optimization of Machining Parameters in abrasive water jet machining (AWJM) Process for Copper Iron Alloy Using RSM and Regression Analysis. The process parameters considered was water pressure, abrasive flow rate, orifice diameter, focusing nozzle diameter and standoff distance. They studied the effect of five process parameters on metal removal rate (MRR) and surface roughness (SR) of the Copper Iron alloy using regression analysis.

Derzija Begic-Hajdarevic et al. [10] studied the effects of material thickness, traverse speed and abrasive mass flow rate during abrasive water jet cutting of aluminum on surface roughness. They analyzed that traverse speed has great effect on the surface roughness at the bottom of the cut and the correlation between the surface roughness and other abrasive water jet cutting variables.

B. Satyanarayana and G. Srikar [11] investigated work on optimization of abrasive water jet machining process parameters using Taguchi grey relational analysis (TGRA). The process parameters are chosen as abrasive flow rate, pressure, and standoff distance. From ANOVA it is found that water jet pressure has more significant effect on kerf width and MRR rather than abrasive flow rate and standoff distance. They analyzed that predicted $\mathrm{S} / \mathrm{N}$ ratio is nearest to the conformation test $\mathrm{S} / \mathrm{N}$ ratio; this conclude that the TGRA process adopted for optimization of parameters is accurate.

Deepak Doreswamy et al. [12] carried out work to find the effect of stand-off distance and feed rate on kerf width and surface roughness for machining of D2 heat treated steel using abrasive water jet.They observed that, in single pass machining, for the same increase in standoff distance, the top kerf width increases $(\approx 18 \%)$ whereas the bottom kerf width 


\section{International Journal of Science and Research (IJSR) \\ ISSN (Online): 2319-7064 \\ Index Copernicus Value (2013): 6.14 | Impact Factor (2014): 5.611}

decreases $(\approx 25 \%)$. Also, the increase in standoff distance and feed rate increases the surface roughness $(\mathrm{Ra})$ value.

T. V. K. Gupta et al. [13] investigated the role of process parameters on pocket milling on SS 304 material with abrasive water jet machining (AWJM) technique. They considered process parameters are Abrasive size, flow rate, standoff distance and traverse speed. Pockets of definite size are machined to investigate surface roughness (SR), material removal rate (MRR) and pocket depth. ANOVA for individual output parameter has been studied to know the significant process parameters. It was observed that higher traverse speeds gives a better finish because of reduction in the particle energy density and lower depth is also observed. Also, Increase in the standoff distance and abrasive flow rate reduces the rate of material removal as the jet loses its focus and occurrence of collisions within the particles.

G.A Escobar-Palafox et al. [14] carried out work on characterization of abrasive water-jet process for pocket milling in Inconel 718. They considered a design of experiments approach and process variables as water pressure, nozzle stand-off distance, traverse speed, nozzle orifice diameter, abrasive mass flow rate and tool-path step over distance. Statistical analysis was carried out in order to develop mathematical models which include process variable interactions and quadratic terms. The results showed that water pressure has a non-linear behavior and is of paramount importance for controlling the depth of cut and geometrical errors. In addition, nozzle diameter and the interaction between feed rate and abrasive mass flow are critical factors affecting the depth of cut.

P. R. Kubade and V. S. Jadhav [15] investigated the influence of EDM process parameters on electrode wear rate, material removal rate and radial overcut while machining of AISI D3 material. It was found that the MRR is mainly influenced by (Ip). Electrode wear rate was mainly influenced by peak current (Ip) and pulse on time $\left(\mathrm{T}_{\text {on }}\right)$, duty cycle (t) and gap voltage (Vg) has very less effect on electrode wear rate. Peak current (Ip) has the most influence on radial overcut then followed by duty cycle (t) and pulse on time $\left(\mathrm{T}_{\text {on }}\right)$ with almost very less influence by gap voltage (Vg).

P. R. Kubade et al. [16] had carried out work on parametric study and optimization of wire electrical discharge machining (WEDM) parameters for Titanium diboride (TiB2) component. The experiments were conducted using Taguchi's L27 orthogonal array. It was found that pulse-on time and pulse-off time has most significant effect on MRR whereas wire feed rate is insignificant. In addition, pulse-off time has most effect on surface roughness followed by pulseon time and wire feed rate.

Kashid D. V., P. R. Kubade et al. [17] investigated the effect of process parameters on material removal rate in wire-cut electrical discharge machining of steel grade EN9 component. Three process parameters selected for this study; Pulse-on time, Pulse-off time and wire feed. Taguchi's method, analysis of variance (ANOVA) and signal to noise ratio (SN Ratio) are used for investigation. It was concluded that pulse-on time and pulse-off time are the most significant influencing machining parameters affecting material removal rate. The wire feed parameter have very less effect on material removal rate.

Table 1: Effect of Processing Parameters on Processing Outputs in AWJM

\begin{tabular}{|c|c|c|c|c|c|}
\hline $\begin{array}{l}\text { Performance } \\
\text { Measures } \rightarrow\end{array}$ & & \multirow{2}{*}{ MRR } & \multirow{2}{*}{$\begin{array}{c}\text { Surface } \\
\text { Roughness }\end{array}$} & \multirow{2}{*}{$\begin{array}{c}\text { Kerf } \\
\text { Width }\end{array}$} & \multirow{2}{*}{$\begin{array}{l}\text { Depth } \\
\text { of Cut }\end{array}$} \\
\hline $\begin{array}{l}\text { Process Parameters } \\
\downarrow\end{array}$ & & & & & \\
\hline \multirow[t]{2}{*}{ PRESSURE } & Increases & $\uparrow$ & $\begin{array}{c}\text { 个 to some } \\
\text { extent }\end{array}$ & $\uparrow$ & $\uparrow$ \\
\hline & Decreases & & & & \\
\hline \multirow{2}{*}{ TRAVERSE SPEED } & Increases & $\uparrow$ & $\uparrow$ & $\downarrow$ & \\
\hline & Decreases & & & & \\
\hline \multirow{2}{*}{$\begin{array}{l}\text { STAND-OFF } \\
\text { DISTANCE }\end{array}$} & Increases & & $\begin{array}{c}\text { 个 to some } \\
\text { extent }\end{array}$ & & \\
\hline & Decreases & & & & \\
\hline \multirow{2}{*}{$\begin{array}{l}\text { ABRASIVE FLOW } \\
\text { RATE }\end{array}$} & Increases & $\uparrow$ & $\downarrow$ & $\uparrow$ & \\
\hline & Decreases & & & & \\
\hline \multirow{2}{*}{ WORK FEED RATE } & Increases & $\uparrow$ & & & \\
\hline & Decreases & & & & \\
\hline
\end{tabular}

( $\uparrow)$ Increase ; $(\downarrow)$ Decrease

\section{Summary}

So many investigations so far had done on AWJM process. Study of process parameters such as abrasive flow rate, traverse speed, standoff distance, pressure, abrasive size, orifice diameter and performance measures as Surface roughness (SR), Material removal rate (MRR), kerf width, Depth of cut (DOC) is carried out more by researchers.

From the literature review it is observed that mostly combinations of process parameters like abrasive size, traverse speed, standoff distance and performance measures as DOC, SR, and MRR are investigated. MRR or production is improved by increasing the traverse speed and abrasive flow rate but major problem with increasing traverse speed is that surface roughness and kerf quality are decreased. By increasing abrasive flow rate MRR increases but, decrease surface roughness. So it is important to find the optimum conditions for process parameters to give better quality of cutting surface. It was found that many researchers have employed different optimization techniques like Taguchi method, ANOVA, Regression analysis to find out the optimum cutting condition for AWJM operation. But less work has been reported on Multi-objective optimization of AWJM process. Also very little work has been reported on effect of nozzle and orifice diameter. So, more work is required to be done in this area.

\section{References}

[1] Er. Guru Sewak Kesharwani, "Controlled Depth Milling of Ti-6Al-4V Alloy using Non-spherical (Triangular \& Trapezoidal) Sharp edge shape ceramics abrasive particle in Abrasive Water Jet Machining", International Journal of Scientific \& Engineering Research, Volume 6, Issue 5, pp. 183-188, 2015.

[2] Chithirai Pon Selvan M, Sampath S S, Sawan Shetty, Shivamurthy B, "Investigation of Abrasive Water jet Cutting Surfaces of Alumina Ceramics", International Journal of Emerging Technology and Advanced Engineering, Volume 5, Issue 1, pp.402-407, 2015. 


\section{International Journal of Science and Research (IJSR) \\ ISSN (Online): 2319-7064}

Index Copernicus Value (2013): 6.14 | Impact Factor (2014): 5.611

[3] Ramprasad, Gaurav Upadhyay, Kamal Hassan, "Optimization MRR Of Stainless Steel 403 In Abrasive Water Jet Machining Using Anova And Taguchi Method" , International Journal of Engineering Research and Applications, Volume 5, Issue 5, pp. 8691, 2015.

[4] Vishal Gupta, P.M. Pandey, Mohinder Pal Garg, Rajesh Khanna,N.K.Batra, "Minimization of kerf taper angle and kerf width using Taguchi's method in abrasive water jet machining of marble", In Proceedings of the Third International Conference on Materials Processing and Characterization (ICMPC 2014), Procedia Materials Science 6, pp. 140 - 149, 2014.

[5] P. Shanmughasundaram, "Influence of Abrasive Water jet machining parameters on surface roughness of Eutectic Al-Si Alloy-Graphite Composites", Journal of Materials Physics and Mechanics 19, pp. 1-8, 2014.

[6] D. Sidda Reddy, A. Seshu Kumar, M.Sreenivasa Rao, "Parametric Optimization of Abrasive Water Jet Machining of Inconel $800 \mathrm{H}$ Using Taguchi Methodology" , Universal Journal of Mechanical Engineering 2(5), pp. 158-162, 2014.

[7] M.Sreenivasa Rao, S.Ravinder and A. Seshu Kumar, "Parametric Optimization of Abrasive Water jet Machining for Mild Steel: Taguchi Approach", International Journal of Current Engineering and Technology, Special Issue-2, pp. 28-30, 2014.

[8] Ushasta Aicha, Simul Banerjee, Asish Bandyopadhyay, Probal Kumar Das, "Abrasive Water Jet Cutting of Borosilicate Glass", In Proceedings of the Third International Conference on Materials Processing and Characterisation (ICMPC 2014), Procedia Materials Science 6, pp. 775 - 785, 2014.

[9] K.S. Jai Aultrin, M. Dev Anand, "Optimization of Machining Parameters in AWJM Process for an Copper Iron Alloy Using RSM and Regression Analysis", International Journal of Emerging Engineering Research and Technology, Volume 2, Issue 5, pp. 1934, 2014.

[10] Derzija Begic-Hajdarevic , Ahmet Cekic, Muhamed Mehmedovic, Almina Djelmic, "Experimental Study on Surface Roughness in Abrasive Water Jet Cutting”, In Proceedings of the Twenty Fifth International Symposium on Intelligent Manufacturing and Automation, DAAAM 2014, pp. 394 - 399, 2015.

[11] B.Satyanarayana,G. Srikar, "Optimization of Abrasive water jet machining using TGRA", In Proceedings of the Thirteenth IRF International Conference, ISBN: 978-93-84209-37-7, pp. 135-140, 2014.

[12] Deepak Doreswamy, Akash Valavala, Natt Winitthumkul, Anjaiah Devineni, "Machining of D2 Heat treated steel using AWJ: Effect of Standoff distance and feed rate on kerf width and surface roughness", International Journal of Research in Engineering and Technology, Volume: 03, Issue: 08, pp.417-421, 2014.

[13] T. V. K. Gupta, J. Ramkumar, "Role of Process Parameters on Pocket Milling with Abrasive Water Jet Machining Technique", International Journal of Mechanical, Aerospace, Industrial, Mechatronic and Manufacturing Engineering Vol:7, No:10, pp. 946-951, 2013.
[14] G.A Escobar-Palafox, R.S Gault, K Ridgway, "Characterization of abrasive water-jet process for pocket milling in Inconel 718 ", 5th CIRP Conference on High Performance Cutting 2012, Procedia CIRP 1, pp. $404-408,2012$.

[15] Pravin R. Kubade, V. S. Jadhav, “An Experimental Investigation of Electrode Wear Rate (EWR),Material Removal Rate (MRR) and Radial Overcut (ROC) in EDM of High Carbon-High Chromium Steel (AISI D3)",International Journal of Engineering and Advanced Technology (IJEAT),Volume 1,Issue 5, pp. 135-140, 2012

[16] Pravin R. Kubade, Sunil S. Jamadade, Ravindranath G. Kshirsagar, Rahul C. Bhedasgaonkar, "Parametric Study and Optimization of WEDM Parameters for Titanium diboride TiB2",Volume 2,Issue 4, pp. 1-5, 2015.

[17] Kashid D.V., S.G.Bhatwadekar, S.B.Sangale, P.R.Kubade, "Investigations of Effect of Process Parameters on Material Removal Rate in Wire-cut Electrical Discharge Machining of Steel Grade EN 9", Volume 2,Issue 1, pp. 31-35, 2014.

\section{Author Profile}

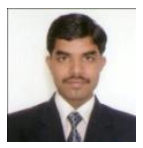

Sudhakar R. Lohar, Scholar of M.E. MechanicalProduction Engineering, K.I.T.'s College of Engineering, Kolhapur-416234, Maharashtra. India.

Pravin R. Kubade, Asst. Prof., Department of Mechanical and Production Engineering, K.I.T.'s College of Engineering, Kolhapur-416234, Maharashtra, India. 